\title{
¿ES REAL EL DIÁLOGO ENTRE TRIBUNALES? CUESTIÓN PREJUDICIAL Y CONTROL DE CONSTITUCIONALIDAD POR VULNERACIÓN DE DERECHOS Y LIBERTADES FUNDAMENTALES ${ }^{1}$
}

\author{
ENCARNACIÓN ROCA TRÍAS \\ Magistrada del Tribunal Constitucional \\ SUSANA GARCÍA COUSO \\ Letrada del Tribunal Constitucional \\ Profesora Titular de Derecho Constitucional \\ Universidad Rey Juan Carlos
}

\begin{abstract}
SUMARIO
I. Introducción. II. Posibilidades de un juez o tribunal ante un supuesto «doble vicio»: contradicción con la Carta e inconstitucionalidad. III. Consecuencias de la doctrina Melki y Abdeli. IV. La posición del TC ante un supuesto «doble vicio»: la importancia de su calificación como órgano judicial a los efectos del art. 267 TFUE. V. Conclusión.
\end{abstract}

\section{INTRODUCCIÓN}

Es de sobra conocida la tensión existente entre los Tribunales Constitucionales de los Estados miembros y el Tribunal de Justicia de la Unión Europea

1 Este artículo tiene como origen la Ponencia «La relación cuestión prejudicial/cuestión de inconstitucionalidad», presentada en la I Jornada-Seminario TC-TS, con el título «Las jurisdicciones europeas y las jurisdicciones superiores de los Estados miembros», celebrada el 21 de septiembre de 2014 en la sede del Tribunal Constitucional. Las opiniones de las autoras son estrictamente personales y ajenas a su condición de Magistrada y Letrada del Tribunal Constitucional, respectivamente.Finalmente, queremos agradecer la generosidad de Xabier Arzoz Santisteban, Letrado del TC, por compartir con nosotras sus conocimientos sobre el Derecho europeo así como sus sugerencias después de la lectura de este trabajo. Así como la ayuda de Carlos Padrós Reig también Letrado del TC.

2 Este trabajo se inserta dentro del proyecto de investigación financiado por el Ministerio de Educación (DER2016-75567-R) «El Tribunal de Justicia de la Unión Europea: Su incidencia en la configuración normativa del proceso civil español y en la protección de derechos fundamentales». 
(TJUE) $)^{3}$. Una tensión que se hace patente tras el planteamiento de cuestiones prejudiciales ante el TJUE en supuestos en los que aunque el asunto se plantee como una cuestión interpretativa del Derecho de la Unión, comprende, además, un problema de derechos fundamentales. Si bien es cierto que el parámetro de interpretación o de control de validez de la cuestión prejudicial es el Derecho de la Unión, no lo es menos que, en la práctica, ambos procedimientos terminan con una decisión de compatibilidad de una norma de un Estado respecto de la Carta de Derechos fundamentales de la Unión Europea (en adelante, CDFUE o Carta) o de la Constitución del Estado; situación que se puede convertir en verdadero motivo de fricción entre ambas jurisdicciones, especialmente con la entrada en vigor del Tratado de Lisboa el 1 de diciembre de 2009, tras el reconocimiento de su eficacia jurídica vinculante ${ }^{4}$. Un acontecimiento de trascendencia para la definición de los derechos y libertades que no puede ser obviado por los Estados firmantes. Cada vez son más numerosas las referencias del TJUE a los derechos fundamentales de la Carta a consecuencia del planteamiento de cuestiones prejudiciales por los órganos judiciales, con la intención de clarificar la adaptación de su normativa a los derechos en ella reconocidos. Así, durante los últimos años, se ha pronunciado sobre determinados derechos como son la igualdad, la dignidad humana, la vida privada y familiar, la tutela judicial efectiva y la propiedad, entre otros.

En relación con nuestro ordenamiento jurídico, ha sido curioso observar, por ejemplo, cómo a través del ejercicio de una materia competencia de la Unión, como es el Derecho de los consumidores, el Tribunal de Justicia se pronuncia sobre una norma procesal española que, finalmente, declara contraria el Tratado de la Unión Europea por vulneración de un derecho reconocido por la Carta; declaración que acabó provocando un cambio legislativo mediante Real Decreto-ley ${ }^{5}$, tras el cual el

3 Para Roca Trías, E., «lo que, en el fondo, siempre late en este tipo de situaciones en las que, como en el espacio europeo, coinciden dos tribunales competentes», es «la defensa de la competencia del Tribunal Constitucional en el ámbito de los derechos fundamentales» (Voto concurrente formulado a la STC 26/2014, de 13 de febrero, FJ 4).

4 De acuerdo con el art. 6.1 del Tratado de la Unión Europea (en adelante, TUE): «La Unión reconoce los derechos, libertades y principios enunciados en la Carta de los Derechos Fundamentales de la Unión Europea de 7 de diciembre de 2000, tal y como fue adoptada el 12 de diciembre de 2007 en Estrasburgo, la cual tendrá el mismo valor jurídico que los Tratados».

5 A través de un Real Decreto-ley —RDL 11/2014, de 5 de septiembre, de medidas urgentes en materia concursal — se ha procedido a modificar, tras el dictado de la STJUE de 17 de julio de 2014, asunto Sánchez Morcillo, el régimen de recursos en los procedimientos de ejecución hipotecaria previsto en el art. 695.4 LEC. En dicha Sentencia se declara vulnerado el derecho de igualdad de armas o de igualdad procesal, como integrante del «principio de la tutela judicial efectiva de los derechos que el ordenamiento jurídico de la Unión confiere a los justiciables, tal y como se garantiza en el artículo 47 de la Carta» (STJUE de 17 de julio de 2014, párrafo 48), pues «resulta contrario a la jurisprudencia del Tribunal de Justicia según la cual las características específicas de los procedimientos judiciales que se ventilan entre los profesionales y los consumidores, en el marco del Derecho nacional, no constituyen un elemento que pueda afectar a la protección jurídica de la que éstos últimos deben disfrutar en virtud de la Directiva 93/13». Y así declara que «[e]l artículo 7, apartado 1, de la Directiva 93/13/ CEE del Consejo, de 5 de abril de 1993, sobre cláusulas abusivas en los contratos celebrados con consumidores, en relación con el artículo 47 de la Carta de los Derechos Fundamentales de la Unión Europea, debe interpretarse 
Tribunal Constitucional (TC) ha decidido por STC 213/2016, de 15 de diciembre, la pérdida parcial de objeto del recurso de inconstitucionalidad planteada respecto de la norma modificada ${ }^{6}$. Es decir, la Ley $1 / 2013$, de 14 de mayo, que contiene normas de protección de deudores hipotecarios. O cómo a través de una interpretación del principio de igualdad distinta de la que hasta ese momento era aplicada en España, de conformidad con el canon establecido por el TC, el TJUE puede llegar a cambiar, como así parece estar sucediendo, las relaciones laborales y funcionariales hasta el momento consideradas constitucionales ${ }^{7}$. También el TJUE se ha pronunciado sobre el principio de no discriminación por razón de $\operatorname{sexo}^{8}$, maternidad $^{9}$ o $\operatorname{edad}^{10}$, generando importantes cambios en las decisiones de los poderes públicos y en la jurisprudencia de los órganos judiciales y del propio TC.

Es evidente que esta situación conlleva inevitablemente el replanteamiento de las funciones de los Tribunales Constitucionales europeos respecto de la protección de derechos y libertades fundamentales y, por ende, de la configuración de su parámetro de control respecto de competencias de la Unión. En tales casos, en los que están en juego los derechos fundamentales: ¿se puede mantener que el control de «comunitariedad» o «europeidad» es diferente al de «constitucionalidad»? No es baladí esta pregunta. De su contestación se derivan otras cuestiones a resolver: ¿Puede el TC realizar un juicio de constitucionalidad sin tener en cuenta la previa decisión del TJUE? ${ }^{11} \mathrm{Y}$ de no existir decisión al respecto, ¿debería proceder a

en el sentido de que se opone a un sistema de procedimientos de ejecución, como el controvertido en el litigio principal, que establece que el procedimiento de ejecución hipotecaria no podrá ser suspendido por el juez que conozca del proceso declarativo, juez que en su resolución final, podrá acordar a lo sumo una indemnización que compense el perjuicio sufrido por el consumidor, en la medida que éste, en su condición de deudor ejecutado, no puede recurrir en apelación contra la resolución mediante la que se desestime su oposición a la ejecución, mientras que el profesional, acreedor ejecutante, sí puede interponer recurso de apelación contra la resolución que acuerde el sobreseimiento de la ejecución o declare la inaplicación de una cláusula abusiva». Vid. sobre esta cuestión la STC 148/2016, de 19 de septiembre, aunque no se trate de una Sentencia resultante de un proceso de control de constitucionalidad.

6 Recurso de inconstitucionalidad interpuesto por más de cincuenta diputados del Grupo parlamentario socialista del Congreso de los Diputados.

7 Vid. las más recientes SSTJUE de 14 de septiembre de 2016, asuntos C-16/15; C-184/2015 y C-197/2015; y C-596/14

8 STJUE de 22 de noviembre de 2012, asunto Elbal Moreno, C-385/11.

9 STJUE de 16 de febrero de 2006, asunto Sarkatzis, C-294/04.

10 STJUE de 13 de noviembre de 2014, asunto Mario Vital Pérez c. Ayuntamiento de Oviedo, C-416/2013, en la que se declaró contrario al Derecho de la Unión la normativa española que fija en 30 años la edad máxima para acceder a una plaza de agente de policía local. No lo ha considerado así en la STJUE de 15 de noviembre de 2016, asunto Gorka Salaberría Sorondo c. Academia Vasca de Policía y Emergencias, C-258/15, respecto del límite de edad de 35 años para acceder a puestos de la policía autonómica vasca que ejercen funciones operativas y ejecutivas.

11 Los AATC 168/2016, de 4 de octubre (Pleno) y 184 y 185/2016, de 15 de noviembre manifiestan esta tendencia, si bien para el caso de la cuestión de inconstitucionalidad y desde la perspectiva de la falta del requisito del juicio de relevancia. En ellos el Tribunal entendió que dado que la Sección planteó «casi simultáneamente respecto de los mismos preceptos legales cuestión de inconstitucionalidad ante este Tribunal y cuestión prejudicial ante el Tribunal de Justicia de la Unión Europea (...) no pueda entenderse cumplido, respecto de la admisibilidad de esta [la cuestión de inconstitucionalidad], el requisito de que la norma con rango de ley cuestionada sea «aplicable al caso» (arts. 163 CE y 35.1 LOTC)» (ATC 185/2016, FJ 2). Para el citado 
plantear la correspondiente cuestión prejudicial? ¿Tendría sentido que existieran decisiones contradictorias? Veremos a continuación la jurisprudencia del TJUE en relación con situaciones en las que pueden producirse ambas declaraciones: constitucionalidad y europeidad (CDFUE), advirtiendo ya, que si bien el TJUE admite ambas, dispone que para que un ordenamiento sea conforme con el Derecho de la Unión, debe permitir siempre la posibilidad de un pronunciamiento posterior del TJUE a través del planteamiento de la cuestión prejudicial por cualquier órgano judicial.

Este artículo no quiere sino poner de relieve y reflexionar sobre los problemas que suscita el hecho de que dos Tribunales, competentes en materia de protección de derechos fundamentales e interpretadores de un mismo ordenamiento jurídico (art. $93 \mathrm{CE}$ ), puedan emitir juicios paralelos sobre una misma norma y en virtud de parámetros diferentes.

\section{POSIBILIDADES DE UN JUEZ O TRIBUNAL ANTE UN SUPUESTO «DOBLE VICIO»: INCONSTITUCIONALIDAD Y CONTRADICCIÓN CON LA CARTA}

El Tribunal de Justicia dictó en el 2010 una importante Sentencia, la STJUE de 22 de junio de 2010, asunto Melki y Abdeli ${ }^{12}$, C-188/10 y C189/10, sobre la relación entre cuestión prejudicial-cuestión de inconstitucionalidad. Dicha Sentencia

\footnotetext{
Tribunal, «estando pendiente de resolución una cuestión prejudicial planteada por el órgano judicial sobre una norma legal, por entender que puede ser incompatible con el Derecho de la Unión Europea, no cabe que ese órgano plantee cuestión de inconstitucionalidad sobre esa misma norma hasta que el Tribunal de Justicia de la Unión Europea resuelva. La eventual incompatibilidad de la ley nacional con el Derecho de la Unión sería causa de su inaplicabilidad en el proceso y, por tanto, faltaría una de las condiciones exigidas para la admisibilidad de la cuestión de inconstitucionalidad: que la norma con rango de ley cuestionada sea 'aplicable al caso' (arts. 163 CE y 35.1 LOTC). El planteamiento simultáneo en el presente caso de la cuestión prejudicial ante el TJUE y de la cuestión de inconstitucionalidad determina, en consecuencia, la inadmisibilidad de esta por incumplimiento del requisito de la aplicabilidad (art. 37.1 LOTC)» (ATC 168/2016, FJ 4). En este sentido ya se pronunciaron Ferreres Comella, V.: «El problema del doble vicio en que pueden incurrir las leyes nacionales: infracción de la Constitución e infracción del Derecho de la Unión Europea. A propósito del caso Melki», en Actualidad Jurídica Uría Menéndez, n. ${ }^{\circ}$ 28, 2011, pp. 60 y 61, y Cruz Villalón, P. y REQUejo, J.L.: «La relación entre la cuestión prejudicial y la cuestión de inconstitucionalidad», RDCE, n. ${ }^{\circ}$ 50, 2015, pp. 173-194. Sobre este tema vid. también Ollero Tassara, A.: «Ajuste entre Tribunales», ponencia presentada en las Jornadas de Trabajo celebradas en la Corte Constitucional de Austria, del 9 al 11 de noviembre de 2016 (Viena), que será próximamente publicada en la web oficial del TC.

12 Vid. al respecto Ferreres Comella, V.: «El problema del doble vicio», op. cit., pp. 57-61; SARMIENTO, D.: «Cuestión prejudicial y control previo de constitucionalidad. Comentario a la Sentencia Melki del Tribunal de Justicia de la Unión Europea», REDE, 2011, pp. 99-109; GAROT, M.J.: «El caso Melki, la cuestión prejudicial y los Tribunales Constitucionales. A propósito de la STJUE, C-188/10 y C-189/10, de 22 de junio de 2010», en Noticias de la Unión Europea, n. ${ }^{\circ}$ 237, Sección de Jurisprudencia del Tribunal de Justicia, Abril 2012, Ed. Wolters Kluwer España; Cruz Villalón, P. y ReQUejo, J.L.: «La relación...», op. cit., pp. 173-194; y AA.VV., La cuestión prejudicial europea, dir. R. Alonso García y J. I. Ugartemendia Eceizabarrena, European Inkling (EUi), n. ${ }^{\circ}$ 4, 2014.
} 
fue dictada por la Gran Sala del TJUE tras enjuiciar la Ley francesa que, en el año 2009, establecía el carácter preferente del planteamiento de la cuestión de inconstitucionalidad — «cuestión prioritaria de constitucionalidad»— ante el Consejo Constitucional francés, respecto de la formulación de la cuestión prejudicial ante el Tribunal de Justicia. De sus fundamentos se extrae una conclusión importante: no existe una prioridad a favor del planteamiento de la cuestión prejudicial respecto del de la de constitucionalidad, siempre que se dé la opción al órgano judicial de que en cualquier momento del procedimiento pueda plantear la cuestión prejudicial, incluso una vez dictada la Sentencia por el Tribunal Constitucional.

También se dijo que los jueces ordinarios deben poder adoptar toda medida necesaria para asegurar la tutela judicial provisional de los derechos conferidos por el ordenamiento de la Unión y que los jueces ordinarios deben poder dejar inaplicada la ley nacional controvertida, una vez finalizado el procedimiento incidental de control de constitucionalidad, si la consideraran contraria al Derecho de la Unión. Y ello aunque el Tribunal Constitucional haya descartado la inconstitucionalidad de la ley, pues es al tribunal remitente a quien incumbe verificar si la legislación nacional controvertida en los asuntos principales puede interpretarse conforme a esas exigencias del Derecho de la Unión. Únicamente, y como excepción, debe ser previo el planteamiento de la cuestión prejudicial respecto de la validez de las Directivas, dado que sólo el TJUE tiene competencia para declarar la invalidez de un acto de la Unión.

Cuestión similar se planteó respecto del ordenamiento austríaco. Dicho ordenamiento, establece que el Alto Tribunal de las jurisdicciones civil y penal y los tribunales ordinarios que han de resolver en segunda instancia, se encuentran obligados a solicitar de su Tribunal Constitucional la anulación de la ley ordinaria de que se trate, en caso de duda sobre su constitucionalidad, dado que no tienen competencia para anular leyes ordinarias por inconstitucionalidad. Conviene precisar al respecto que, en una resolución de 14 de marzo de 2012, el Verfassungsgerichtshof adoptó una importante decisión que le apartó de su reiterada jurisprudencia según la cual los órganos judiciales debían inaplicar las disposiciones legales contrarias al Derecho de la Unión en virtud del principio de primacía de éste, para pasar a considerar que «el control de la constitucionalidad de las leyes nacionales que lleva a cabo en el marco del procedimiento de control general de las leyes (...), debía extenderse a las disposiciones de la Carta». El citado Tribunal consideró que si en el marco del procedimiento de control de constitucionalidad, los derechos garantizados por el CEDH podían invocarse ante él como derechos de rango constitucional, también el principio de equivalencia, tal y como resulta de la jurisprudencia del Tribunal de Justicia, exigía que este control general de las leyes comprenda los derechos garantizados por la Carta ${ }^{13}$.

13 Así se pone de manifiesto en los Antecedentes de la STJUE de 11 de septiembre de 2014, asunto A c. B y otros (C-112/13). Sobre la Sentencia austríaca de 14 de marzo de 2012, vid. Arzoz 
Ante esta situación, un órgano judicial austríaco remitió tres cuestiones prejudiciales al TJUE, respecto de la citada resolución, precisamente por afirmar que los tribunales carecen de competencia para dejar de aplicar una ley contraria a la Carta, estando obligados a solicitar al Verfassungsgerichtshof la anulación con carácter general de dicha ley. Es por ello que se solicita, en la primera de las tres cuestiones prejudiciales, que es lo que en este momento nos interesa, «que se dilucide si el Derecho de la Unión, y en particular el artículo 267 Tratado de Funcionamiento de la Unión Europea (TFUE), debe interpretarse en el sentido de que se opone a una normativa nacional, como la controvertida en el litigio principal, según la cual los tribunales ordinarios que resuelven en apelación o en última instancia están obligados, cuando consideren que una ley nacional es contraria al artículo 47 de la Carta, a solicitar al Tribunal Constitucional, en el marco del procedimiento que se sustancia ante ellos, la anulación con carácter general de la ley en lugar de limitarse a dejar de aplicarla en el caso concreto».

El Tribunal de Justicia, en su Sentencia de 11 de septiembre de 2014, asunto A c. B y otros, C-112/13, como respuesta a la cuestión planteada, vuelve a acoger la doctrina sentada en la Sentencia Melki y Abdeli, y dice: «El Derecho de la Unión, y en particular el artículo 267 TFUE, debe interpretarse en el sentido de que se opone a una normativa nacional, como la controvertida en el litigio principal (...) en la medida en que el carácter prioritario de ese procedimiento teng a como efecto impedir, tanto antes de la presentación de la referida solicitud al órgano jurisdiccional nacional competente para ejercer el control de constitucionalidad de las leyes como, en su caso, después de la resolución del citado órgano sobre esa solicitud, que los tribunales ordinarios ejerzan su facultad o cumplan su obligación de plantear cuestiones prejudiciales al Tribunal de Justicia. En cambio, el Derecho de la Unión y, en particular el articulo 267 TFUE, debe interpretarse en el sentido de que no se opone a tal normativa nacional cuando los tribunales ordinarios sigan facultados para plantear al Tribunal de Justicia toda cuestión prejudicial que consideren necesaria, en cualquier momento del procedimiento que estimen apropiado, e incluso una vez finalizado el procedimiento incidental de control general de leyes, para adoptar toda medida necesaria a fin de garantizar la tutela judicial provisional de los derechos conferidos por el ordenamiento jurídico de la Unión, y para dejar inaplicada, una vez finalizado ese procedimiento incidental, la disposición legislativa nacional controvertida si la consideran contraria al Derecho de la Unión».

Otra de las Sentencias del TJUE, en relación con el tema que nos ocupa, ha sido la dictada el 4 de junio de 2015, asunto Kernkraftwerke Lippe-Ems GmbH c. Hauptzollamt Osnabrück, C-5/14. Por lo que al tema nos interesa, un tribunal alemán pregunta al TJUE acerca de la posibilidad de plantear cuestiones prejudiciales mientras está pendiente el procedimiento iniciado ante el Bundesverfassungsgericht ${ }^{14}$. Tras rea-

SAntisteban, X.: La tutela de los derechos fundamentales de la Unión Europea por el Tribunal Constitucional, INAP, Madrid, 2015, pp. 53-59.

14 En concreto, planteaba lo siguiente: «El artículo 267 TFUE, párrafo segundo, en relación con su párrafo primero, letra b), ¿faculta al órgano jurisdiccional de un Estado miembro a plantear al Tribunal de Justicia de la Unión Europea cuestiones que se susciten en el contexto de la legalidad de una ley nacional en relación con la interpretación del Derecho de la Unión 
lizar unas consideraciones previas que hacen referencia principalmente a las Sentencias ya citadas, el Tribunal de Justicia responde que: "el artículo 267 TFUE debe interpretarse en el sentido de que un órgano jurisdiccional nacional, que albergue dudas acerca de la compatibilidad de una normativa nacional, tanto con el Derecho de la Unión como con la Constitución del Estado miembro de que se trate, no está privado de la facultad ni, en su caso, exento de la obligación de plantear al Tribunal de Justicia cuestiones sobre la interpretación o la validez de ese Derecho por el hecho de que estépendiente un procedimiento incidental de control de la constitucionalidad de esa misma normativa ante el órgano jurisdiccional nacional encargado de ejercer ese control» (apartado 39).

Las conclusiones a las que llega el TJUE en estas decisiones pueden resumirse de la siguiente manera. El Tribunal de Justicia entiende que toda disposición de un ordenamiento jurídico nacional, aun cuando sea de rango constitucional, o toda práctica legislativa, administrativa o judicial, que redujese la eficacia del Derecho de la Unión por el hecho de negar al juez competente para aplicar ese derecho la facultad de hacerlo, será incompatible con las exigencias inherentes a la propia naturaleza del Derecho de la Unión en el mismo momento de esa aplicación, debiendo llevar a cabo todo lo necesario para excluir las disposiciones legislativas nacionales que pudiesen constituir un obstáculo a la plena eficacia de las normas de la Unión. Así sucedería, dice el TJUE, (i) en la hipótesis de un conflicto entre una disposición del Derecho de la Unión y una ley nacional, si la solución de dicho conflicto quedase reservada a una autoridad distinta del juez encargado de la aplicación del Derecho de la Unión, investida de una facultad de apreciación propia, aun cuando el obstáculo así resultante para la plena eficacia de dicho Derecho no fuese más que temporal; (ii) o con la existencia de un recurso obligatorio ante el juez constitucional que pudiese impedir que el juez nacional pueda plantear cuestiones sobre la interpretación o sobre la validez del Derecho de la Unión. En definitiva, para el citado Tribunal, el funcionamiento del sistema de cooperación entre el Tribunal de Justicia y los tribunales nacionales, establecido por el art. 267 TFUE y el principio de primacía del Derecho de la Unión, requiere que el juez nacional tenga la facultad de plantear al Tribunal de Justicia toda cuestión prejudicial que considere necesaria en cualquier fase del procedimiento que estime apropiada, e incluso una vez finalizado un procedimiento incidental de control de constitucionalidad.

\section{CONSECUENCIAS DE LA DOCTRINA MELKI Y ABDELI}

Los razonamientos dados por el TJUE en las Sentencias antes mencionadas no hacen sino advertir de su competencia en el conocimiento de los asuntos que

también en el caso de que aquel órgano jurisdiccional no sólo tenga, por una parte, dudas acerca de la conformidad de esta ley con el Derecho de la Unión sino que, por otra, estime igualmente que dicha ley nacional es contraria a la Constitución nacional, y, por ello, haya acudido ya, en un procedimiento paralelo, ante el Tribunal Constitucional —único competente, en virtud del Derecho nacional, para pronunciarse sobre la inconstitucionalidad de las leyes-, que, sin embargo, no se ha pronunciado todavía?». 
recaen sobre las materias competencia de la Unión. Incluso - y esto lo que aporta la Sentencia A. o B.- en el caso de que se encuentre centralizado el control de la Carta en el Tribunal Constitucional. En efecto, lo que es más significativo de esta Sentencia es el reconocimiento por el Tribunal de Justicia de la facultad, a la que no cabe plantear impedimentos por parte de los Estados miembros, de que los órganos judiciales puedan presentar una cuestión prejudicial en cualquier fase del procedimiento.

Con estas decisiones, si bien pudiera parecer que lo que se favorece es el llamado «diálogo» ${ }^{15} \mathrm{o}$ «cooperación» entre Tribunales, al conciliar ambos mecanismos, lo que el Tribunal de Justicia asegura es la posibilidad siempre abierta, tras el reconocimiento de la posibilidad del planteamiento de una cuestión prejudicial en cualquier momento y por cualquier órgano judicial, de ejercer su derecho a la última palabra ${ }^{16}$; así como, también, equiparar a todo Juez o Tribunal que se considere como tal a los efectos del art. 267 TFUE $^{17}$. El TJUE consigue que, en la práctica, aunque se permita una primera evaluación por los Tribunales Constitucionales, su competencia quede asegurada. Incluso las Sentencias dictadas por aquellos Tribunales Constitucionales que incluyen la Carta como parámetro de control en el ámbito de los derechos y libertades fundamentales, sólo podrán ser consideradas «firmes» tras el dictado de una Sentencia del Tribunal de Luxemburgo que las ratifique o las contradiga.

El hecho de que el Tribunal de Justicia considere contrario a la Carta que las regulaciones de los Estados miembros no permitan a sus órganos judiciales plantear una cuestión prejudicial en cualquier momento del conocimiento del asunto,

15 Sobre el diálogo entre Tribunales vid. AA.VV.: Tribunal Constitucional y diálogo entre tribunales, XVIII Jornadas de la Asociación de Letrados del Tribunal Constitucional, Tribunal Constitucional y Centro de Estudios Políticos y Constitucionales, Madrid 2013; Vergottini, G. de: Más allá del diálogo entre Tribunales (Comparación y relación entre jurisdicciones), Cuadernos Civitas, 2010; GARCía RocA, J.: «El diálogo entre el Tribunal de Derechos Humanos, los Tribunales Constitucionales y otros órganos jurisdiccionales en el espacio convencional europeo», en Diálogo jurisprudencial en derechos humanos: entre tribunales constitucionales $y$ cortes internacionales. In memoriam Jorge Carpizo, generador incansable de diálogos, coord. E. Ferrer Mac - Gregor y A. Herrera García, Tirant lo Blanch, Valencia, pp. 219-241; y Bustos GisBerT, R.: «XV proposiciones generales para una teoría de los diálogos judiciales», REDC, n. ${ }^{\circ} 95,2012$, pp. 13-63.

16 Vid. sobre esta cuestión, DíEz-Hochleitner, J.: «El derecho a la última palabra: ¿Tribunales Constitucionales o Tribunal de Justicia de la Unión?», en Tribunal Constitucional y diálogo entre tribunales, XVIII Jornadas de la Asociación de Letrados del Tribunal Constitucional, Tribunal Constitucional y Centro de Estudios Políticos y Constitucionales, Madrid, 2013, pp. 57-108.

17 En este sentido, cabe hacer referencia a la STJUE de 5 de abril de 2016, asunto Puligienica Facility Esco, C-689/13. En ella, el TJUE niega la posibilidad de cualquier obstaculización de la facultad u obligación de los órganos judiciales de plantear una petición de decisión prejudicial, al resolver sobre si el art. 267 TFUE se opone a una disposición nacional —el art. 99.3 del Código de Procedimiento Contencioso-Administrativo italiano_ que obliga a una Sala de un Tribunal a remitir al Pleno una cuestión relativa a la interpretación o validez del Derecho de la Unión cuando aquella no comparte su orientación, no permitiéndole plantear directamente una cuestión prejudicial (párrafo 29). Un comentario sobre la citada Sentencia puede verse en REQUEJO PAGÉS, J.L.: «La competencia para preguntar. De nuevo sobre el concepto de órgano jurisdiccional en el sentido del artículo 267 TFUE. El caso de la discrepancia entre el pleno y las salas de un órgano judicial», en Actualidad Administrativa, n. ${ }^{\circ}$ 6, Junio 2016. 
debe ser tenido en cuenta a la hora de reflexionar sobre cuál es la posición y función de los Tribunales Constitucionales en el sistema judicial de la Unión Europea. A nadie se le escapan los problemas que puede suscitar que tras una Sentencia en la que se declara la constitucionalidad de una ley nacional en ejecución de una materia de la Unión, impugnada por la vulneración de los derechos, se dicte otra posterior por el TJUE en sentido contrario. O que se planteara un recurso de amparo contra una decisión judicial que aplicara la ley declarada constitucional tras haber sido considerada por el Tribunal de Justicia contraria al Derecho de la Unión. En estos casos, ¿qué le resta por hacer al TC cuando los órganos judiciales no plantean cuestión de inconstitucionalidad respecto de una ley nacional ya interpretada por el Tribunal de Justicia en sentido contrario a la jurisprudencia constitucional? ¿Y si se plantea una cuestión de inconstitucionalidad y la interpretación en materia de derechos y libertades fundamentales ya ha sido realizada por el Tribunal de Justicia? También cabe preguntarse de qué hubiera servido al Tribunal Constitucional haber declarado constitucional, conforme a su parámetro de constitucionalidad, una ley que es finalmente modificada por el Estado en aplicación de una Sentencia del TJUE que la ha estimado contraria a los Derechos de la Carta.

Los Tribunales Constitucionales han dejado de tener el monopolio sobre la interpretación de los derechos y libertades fundamentales (art. 10.2 CE). Es más, en aquellos casos en que afecte a derechos fundamentales relacionados con la competencia de la UE, podría afirmarse que han dejado de tener el control. En el caso de la Unión Europea el problema viene marcado por un nuevo elemento que hasta ahora no se ha tenido en cuenta de forma correcta: la competencia (art. 93 $\mathrm{CE})^{18}$. También en el ámbito de los derechos fundamentales implicados en materias de Derecho europeo rige dicho principio, pues, en definitiva los derechos fundamentales no dejan de ser una materia transversal que acompaña a la materia de la que bien la Unión bien el Estado son competentes. No podemos olvidar que la Carta es vinculante para los Estados miembros, por lo que, confirmada la competencia de la Unión, es al TJUE al que corresponde emitir un juicio sobre su interpretación ${ }^{19}$.

18 Como ha afirmado Martín y PÉrez de NANClares, J.: «La posición de los Estados miembros ante la evolución de la Unión europea: comprometidos con el proceso de integración, convencidos de la necesidad de reforzar los rasgos de intergubernabilidad», REDCE, n. ${ }^{\circ} 50,2015$, pp. 139 y 140, «no cabe duda de que el acercamiento a ese nuevo espacio europeo desde una concepción basada en el pluralismo constitucional (constitutional pluralism) dentro de un marco multinivel (multinivel constitutionalism) resulta sumamente atractiva y permite explicar satisfactoriamente el reparto de funciones entre los diferentes niveles (incluido la función judicial de los respectivos tribunales) con base en el principio de competencia y no del de jerarquía». Para Cruz Villalón, P. y Requejo, J.L.: «La relación entre la cuestión prejudicial y...», op. cit., p. 176, la relación entre el Derecho de la Unión y los diversos ordenamientos nacionales es «una relación difícil, desde el momento en que está excluida la posibilidad de articularla a partir del principio de jerarquía y sólo en términos muy relativos cabe construirla con el de competencia».

19 Como afirman Cruz Villalón, P. y Requejo, J.L.: «La relación entre la cuestión prejudicial y...», op. cit, p. 177, «en el dominio de los derechos fundamentales, que es el de las normas constitucionales 
Ya en las Declaraciones 1/1992, de 1 de julio y 1/2004, de 13 de diciem$\mathrm{bre}^{20}$, el TC realizaba algunas consideraciones sobre el alcance y contenido de un precepto «clave» como es el art. $93 \mathrm{CE}$. Un precepto «de índole orgánico procedimental» ${ }^{21}$, en cuya virtud es posible la atribución del ejercicio de competencias derivadas de la Constitución a organizaciones o instituciones internacionales, y «fundamento último ${ }^{22}$ de la incorporación al proceso de integración europea y de la vinculación al Derecho comunitario. En concreto en la DTC 1/2004, FJ 2, se afirmó: «El art. $93 \mathrm{CE}$ es sin duda soporte constitucional básico de la integración de otros ordenamientos con el nuestro, a través de la cesión del ejercicio de competencias derivadas de la Constitución, ordenamientos llamados a coexistir con el Ordenamiento interno, en tanto que ordenamientos autónomos por su origen. En términos metafóricos podría decirse que el art. $93 \mathrm{CE}$ opera como bisagra mediante la cual la Constitución misma da entrada en nuestro sistema constitucional a otros ordenamientos jurídicos a través de la cesión del ejercicio de competencias. De este modo se confiere al art. $93 \mathrm{CE}$ una dimensión sustantiva o material que no cabe ignorar.»

Para a renglón seguido advertir que: «Producida la integración debe destacarse que la Constitución no es ya el marco de validez de las normas comunitarias, sino el propio Tratado cuya celebración instrumenta la operación soberana de cesión del ejercicio de competencias derivadas de aquélla, si bien la Constitución exige que el Ordenamiento aceptado como consecuencia de la cesión sea compatible con sus principios y valores básicos y añadir que «Como se deriva del mecanismo contenido en el propio precepto constitucional, tampoco cabe ignorar la necesidad de proporcionar a los organismos internacionales en cuyo favor se ha cedido el ejercicio de las competencias los instrumentos indispensables para garantizar el cumplimiento del Derecho por ellos creado, función que sólo puede verse obstaculizada por un entendimiento inadecuado del citado precepto constitucional y de su sustancia integracionista. De ahí que sea imprescindible una interpretación que atienda a la insoslayable dimensión de integración comunitaria que el precepto constitucional comporta.»

No sorprende encontrar Sentencias del Tribunal de Justicia en las que advierte de su propia incompetencia para conocer de las cuestiones prejudiciales planteadas en el ámbito de los derechos y libertades fundamentales ${ }^{23}$. Los

sustantivas o materiales, la vocación normativa de la Unión es tan legítima como la de los Estados miembros; con mayor razón, si cabe, tras la entrada en vigor de la Carta de los Derechos Fundamentales».

20 Vid. la opinión sobre dicha Declaración y el devenir que ha sufrido tras el dictado de Sentencias posteriores, de Arzoz Santisteban, X.: La tutela de los derechos fundamentales..., op. cit., pp. 75 a 110. Dicha resolución es calificada por el citado autor de "prometedora».

21 STC 28/1991, de 14 de febrero, FJ 4; DTC 1/1992, FJ 4 y DTC 1/2004, de 13 de diciembre, FJ 2.

22 DTC 1/2004, de 13 de diciembre, FJ 2.

23 En cuestiones prejudiciales planteadas por órganos judiciales españoles, ha declarado su incompetencia, por ejemplo, en la STJUE de 27 de marzo de 2014, asunto Emiliano Torralbo, C-265/13, en relación al pago de las tasas judiciales en caso de interposición de un recurso de apelación en el ámbito de la legislación 
Tribunales Constitucionales, a diferencia de la postura que ha adoptado el TJUE, no se ven obligados a decidir sobre ella antes de pronunciarse sobre derechos fundamentales, pudiendo emitir un juicio de constitucionalidad. Ahora bien, su juicio tendrá el mismo valor, en el ámbito de la Unión, que el de cualquier órgano judicial, pues el Estado no puede obstaculizar, en los términos ya expuestos, el planteamiento de una cuestión prejudicial por cualquier Juez o Tribunal.

Admitámoslo, la interpretación de los derechos fundamentales en el ámbito de las competencias de la Unión se encuentra en manos del Tribunal de Justicia, quedando los Tribunales Constitucionales de los Estados miembros vinculados a esa interpretación. Como el resto de los poderes del Estado, deben asumir las consecuencias de la decisión de ceder competencias a favor de organizaciones internacionales adoptada en su día por la instancia constitucionalmente competente para ello (art. $93 \mathrm{CE}$ ). La Constitución no es el marco de validez de las normas europeas, «sino el propio Tratado cuya celebración instrumenta la operación soberana de cesión del ejercicio de competencias derivadas de aquélla» ${ }^{24}$. La interpretación de la delimitación de competencias entre la Unión y los Estados miembros, necesariamente previa a la discusión sobre la interpretación de los derechos, es una cuestión que compete al Tribunal de Luxemburgo, pues si no existe competencia europea no cabe intervención del TJUE ${ }^{25}$.

social (vid. STC 140/2016, de 21 de julio, dictada como consecuencia de un recurso de inconstitucionalidad interpuesto contra diversos preceptos de la Ley 10/2012, de 20 de noviembre, por la que se regulan determinadas tasas en el ámbito de la Administración de Justicia y del Instituto Nacional de Toxicología y Ciencias Forenses); ha dictado, sin embargo, la STJUE de 30 de junio de 2016, asunto Direcția Generală Regională a Finanțelor Publice Brașov, C-205/15, admitiendo su competencia en relación con la exención del pago de determinadas tasas judiciales a las autoridades públicas en Rumanía. También, en la STJUE de 8 de diciembre de 2016, asunto Eurosaneamientos y otros, C-532/15 y C-538/15, ha decidido su incompetencia respecto de algunas de las cuestiones planteadas por el órgano judicial en materia servicios prestados por los Procuradores y el sometimiento a un arancel.

24 DTC 1/2004, de 13 de diciembre, FJ 2. Ahora bien, igualmente se afirma que «la cesión constitucional que el art. $93 \mathrm{CE}$ posibilita tiene a su vez límites materiales que se imponen a la propia cesión. Esos límites materiales, no recogidos expresamente en el precepto constitucional, pero que implícitamente se derivan de la Constitución y del sentido esencial del propio precepto, se traducen en el respeto de la soberanía del Estado, de nuestras estructuras constitucionales básicas y del sistema valores y principios fundamentales consagrados en nuestra Constitución, en el que los derechos fundamentales adquieren sustantividad propia (art. 10.1 CE)».

25 Explica Roca Trías, E., en su Voto concurrente a la STC 26/2014, de 13 de febrero, que «el derecho de la Unión Europea no es Derecho internacional en el territorio de los Estados miembros; las decisiones no son de la Unión Europea, sino de sus miembros que se sientan en los organismos comunitarios y en el Parlamento europeo y, por ello, los Reglamentos tienen efecto inmediato en los ordenamientos jurídicos nacionales. Los Estados han cedido soberanía a la Unión Europea y por ello el art. 93 CE establece: 'Mediante Ley orgánica se podrá autorizar la celebración de tratados por los que se atribuya a una organización o institución internacional el ejercicio de competencias derivadas de la Constitución. Corresponde a las Cortes Generales o al Gobierno, según los casos, la garantía del cumplimiento de estos tratados y de las resoluciones emanadas de los organismos internacionales o supranacionales titulares de la cesión'». 


\section{LA POSICIÓN DEL TC ANTE UN SUPUESTO «DOBLE VICIO»: LA IMPORTANCIA DE SU CALIFICACIÓN COMO ÓRGANO JUDICIAL A LOS EFECTOS DEL ART. 267 TFUE}

El TC ha pasado por varias etapas respecto de su relación con el Derecho de la Unión. En un principio, no consideraba el Derecho de la Unión como parámetro o canon directo de constitucionalidad, por lo que entendía que no le competía controlar su aplicación por los poderes públicos nacionales ${ }^{26}$. Posteriormente pasó a controlar la ausencia de planteamiento de la cuestión prejudicial por los órganos judiciales ${ }^{27}$, para, finalmente, plantear sus propias cuestiones prejudicia$l^{28}{ }^{28}$; no parece, sin embargo, que haya continuado con dicha opción ${ }^{29}$.

El TC debe aclarar su posición respecto del Derecho de la Unión y ello pasa por decidir si es o no órgano judicial a los efectos del art. 267 TFUE. Si bien su opción inicial pudiera ser definida como de prevención en relación con su aplicación, con el planteamiento de las tres primeras cuestiones prejudiciales, de

26 Vid. SSTC 28/1991, de 14 de febrero, FJ 7; 143/1994, de 9 de mayo, FJ 8 y 265/de 3 de octubre, FJ 2 b).

27 Vid. SSTC 58/2004, de 19 de abril; 78/2010, de 20 de octubre y 27/2013, de 11 de febrero.

28 ATC 86/2011, de 9 de junio, asunto Melloni. Vid. Arroyo JimÉnez, L.: «Sobre la primera cuestión prejudicial planteada por el Tribunal Constitucional. Bases, contenido y consecuencias», en Administración y justicia: un análisis jurisprudencial, Liber amicorum Tomás-Ramón Fernández, Cizur Menor (Navarra), Civitas, 2012, pp. 51-76; Torres Muro, I.: «La condena en ausencia: unas preguntas osadas (ATC 86/2001, de 9 de junio) y una respuesta contundente (Sentencia del Tribunal de Justicia de la Unión Europea de 26 de febrero de 2013)», REDC, n. ${ }^{\circ}$ 97, 2013, pp. 343-370; y Revenga SÁNChez, M.: «Rectificar preguntando. El Tribunal Constitucional acude al Tribunal de Justicia (ATC 86/2011, de 9 de junio)», REDE, n. ${ }^{\circ}$ 41, 2012, pp. 139-150.

29 García Couso, S.: «La participación del Tribunal Constitucional en la construcción europea de los derechos y libertades fundamentales: adaptarse o quedar desplazado», Revista CEFLEGAL, núms. 187-188 (agosto-septiembre 2016), pp. 127 y 128: «El Tribunal que había formalizado su planteamiento, resolvió, sin embargo, el recurso de amparo, por STC 26/2014, de 13 de febrero, de acuerdo a una lógica bien distinta a la inicial. Si bien decidió conforme al canon fijado por el TJUE en su Sentencia de 26 de febrero de 2013, C-399/11, dictada como consecuencia de las cuestiones prejudiciales planteadas, no lo hizo de forma explícita. En efecto, el cambio de doctrina que sufrió la consolidada jurisprudencia constitucional sobre el derecho a un proceso con todas las garantías (art. 24.2 CE), no lo fue, según parece desprenderse, como consecuencia de su vinculación a la Sentencia dictada por el Tribunal de Justicia, sino a resultas de un juicio propio que encontró apoyo tanto en la jurisprudencia del TEDH como en la del TJUE. De dicha manera de razonar se desprende que el TC únicamente se ve vinculado a la Carta por considerarla un tratado internacional al que se encuentra vinculado ex art. 10.2 CE. No otro sentido se deduce de haberla equiparado al CEDH. Una equiparación que no parece haber tenido en cuenta que la competencia se encontraba plenamente armonizada por la Unión. La CDFUE y su interpretación por el Tribunal de Justicia, se convierten en derecho nacional interno directamente aplicable en competencias de la Unión (art. 93.2 CE), no así cuando son empleados fuera de ellas (art. 10.2 CE). Los efectos derivados de la aplicación de uno y otro precepto, pueden ser distintos. Así pues, una vez apreciado por el TC que la decisión del TJUE se ejercía en el ámbito de su competencia y que la interpretación de las exigencias derivadas de los artículos 47 y 48.2 CDFUE no afectaban a los límites materiales de la Constitución, se mostraba más acertado, en la lógica europea, aplicar el estándar común marcado por el Tribunal de Justicia, cuando, además, la interpretación realizada respetaba la jurisprudencia del TEDH (art. 52.3 CDFUE)»; «así lo proponía la Magistrada doña Encarnación Roca en el Voto particular formulado a la STC 26/2014». 
interpretación y validez, mediante el ATC 86/2011, de 9 de junio, en el asunto Melloni ${ }^{30}$, pasó a considerarse «órgano judicial» a los efectos de su vinculación.

Fuera cual fuera la opción escogida, dado que ambas son posibles al no existir una regulación específica, lo que debe tenerse necesariamente en cuenta es el diseño general del sistema judicial que ha sido ratificado por el Estado español a través de la firma del Tratado de la Unión Europea ${ }^{31}$. Es decir, en cualquier caso debe permitir la prevalencia de la aplicación de la Carta en aquellas materias que son competencias de la Unión. Y es que si bien el diálogo «formal» entre Tribunales existe, como no podía ser de otra manera, el diálogo «real» termina donde empieza la competencia, y, en la práctica, con el ejercicio del derecho a la última palabra $^{32}$. Merece tener presente siempre que el llamado «diálogo» no se entabla únicamente entre el Tribunal Constitucional y el Tribunal de Justicia, sino entre el Tribunal Constitucional y el Tribunal de Justicia en su condición de órgano aglutinador de las distintas tradiciones constitucionales de los Estados miembros

30 Sobre el asunto Melloni y el diálogo entre el TJUE y el TC, vid. Alonso García, R.: El juez nacional en la Encrucijada Europea de los Derechos Fundamentales, Cuadernos Civitas, 2014; Ugartamendía EcEIZAbarrena, J.I. y Ripol Carulla, S.: «Del recato de la jurisprudencia del Tribunal Constitucional sobre la tutela judicial de los DFUE y de las cuestiones y problemas asociados a la misma. (A propósito de la STC 26/2014, de 13 de febrero)», REDE, n. ${ }^{\circ}$ 50, 2014, pp. 105-149; QuAdra-SAlCEDo JANINI, T. de la: «El papel del Tribunal Constitucional y de los tribunales ordinarios en un contexto de tutela multinivel de los derechos fundamentales», Papeles de Derecho Europeo u Integración Regional, WP IDEIR n. ${ }^{\circ} 23,2015$; Arzoz SANTISTEBAN, X.: La tutela de los derechos fundamentales..., INAP, Madrid, $2015 \mathrm{y}$ «Karlsruhe rechaza la doctrina Melloni del Tribunal de Justicia y advierte con el control de la identidad constitucional», REDE, n. ${ }^{\circ} 58$, 2016, pp. 109 a 141; Matía Portilla, J.: «Primacía del derecho de la Unión y derechos constitucionales. En defensa del Tribunal Constitucional», REDC, n. ${ }^{\circ}$ 106, pp. 479-522; Arroyo Jiménez, L.: «Los derechos fundamentales en la Unión Europea y el Tribunal Constitucional», REDA, n. ${ }^{\circ} 174,2015$, pp. 343-361 y Empatía constitucional: Derecho de la Unión Europea y Constitución español, Marcial Pons, 2016; CARMONA ConTreras, A.: «El espacio europeo de los derechos fundamentales: de la Carta a las constituciones nacionales», REDC, n. ${ }^{\circ}$ 107, 2016, pp. 13-40 y RodríGUEZ-IzQUIERdo SERRANO, M.: «Pluralidad de jurisdicciones y tutela de Derechos: los efectos de la integración europea sobre la relación entre el Juez ordinario y el Tribunal Constitucional», REDC, n. ${ }^{\circ} 107,2016$, pp. 117-150.

31 Sobre las opciones escogidas por los Tribunales Constitucionales puede verse un magnífico estudio en Arzoz Santisteban, X.: La tutela de los derechos fundamentales..., op. cit. Dicho autor afirma, en su p. 50, que la posición de la mayoría «parece alinearse con la del Tribunal Constitucional Federal alemán: excluyen su competencia para revisar la compatibilidad de las normas internas de la Unión, asumiendo una estricta división de competencias entre el control de constitucionalidad, que entra de lleno en su jurisdicción original, y el juicio de compatibilidad europea, que según la doctrina Simmenthal, recae en los jueces nacionales ordinarios, en colaboración con el Tribunal de Justicia», sin embargo advierte que no es una posición unánime.

32 En el mismo sentido, García Couso, S.: «La participación...», op. cit., p. 120. Para la autora, la fórmula del «diálogo entre Tribunales» es válida como principio rector de sus relaciones, pero insuficiente, sin embargo, para hacer un diagnóstico de la posición actual del TC en el entramado jurisdiccional de la Unión Europea. Considera que la naturaleza del «diálogo» no es el misma desde la «influencia» que tiene el TEDH en la interpretación de los derechos y libertades fundamentales ex art. 10.2 CE, que desde la "Competencia» que el TJUE ostenta en la interpretación de la Carta respecto de materias de la Unión (art. 93 CE). Entiende que el diálogo termina donde comienza el derecho a la última palabra, si bien puede considerarse que finaliza «provisionalmente» en la medida que las decisiones adoptadas por los Tribunales competentes podrían llegar a ser moduladas, por lo que el diálogo es mucho más fructífero si se produce antes del dictado de la resolución en cuestión a través del planteamiento de una cuestión prejudicial. 
que el TJUE subsume en una interpretación sustantiva uniforme, que, a la postre, conforma el canon, parámetro o estándar supranacional de derechos. Un canon, parámetro o estándar que debe respetar, además, los derechos protegidos por el Convenio europeo para la protección de los derechos humanos y las libertades fundamentales, firmado en Roma el 4 de noviembre de 1950 (CEDH), tal y como son interpretados por el Tribunal Europeo de Derechos Humanos (TEDH); Convenio al que, además, se encuentran adheridos la totalidad de los Estados de la Unión Europea. No debemos olvidar que el art. 52.3 CDFUE establece que, «[e]n la medida en que la presente Carta contenga derechos que se correspondan a derechos garantizados por el Convenio Europeo para la Protección de los Derechos Humanos y de las Libertades Fundamentales, su sentido y alcance serán iguales a los que les confiere dicho Convenio. Esta disposición no impide que el Derecho de la Unión conceda una protección más extensa». Es posible que con el Protocolo n. ${ }^{\circ} 16$ del Convenio de Derechos Humanos, firmado el 2 de octubre de 2013, que en su apartado 1 de artículo 1 del Protocolo establece que «Los altos tribunales de las Partes Contratantes, especificadas de conformidad con el art. 10, podrán solicitar al Tribunal [Europeo de Derechos Humanos] que emita opiniones consultivas sobre cuestiones de principio relativas a la interpretación o aplicación de los derechos y libertades definidos en el Convenio o sus Protocolos», lo que se pretenda es asegurar el respeto del TJUE a la doctrina del Tribunal Europeo de Derechos Humanos; pero eso es harina de otro costal ${ }^{33}$.

Una opción posible sería decidir no querer formar parte de los órganos judiciales de la Unión, dejando en manos de los Tribunales y Jueces ordinarios su labor de aplicación e interpretación del mismo. Ello significaría volver a la situación inicial y, por tanto, desandar el camino recorrido hasta el momento en el que el TC decidió el planteamiento de las tres cuestiones en el asunto Melloni. De optar por esta línea de comportamiento respecto del conocimiento de asuntos correspondientes al ámbito del Derecho de la Unión, lo coherente sería inadmitir aquellas cuestiones de inconstitucionalidad en las que este se encontrara concernido, de forma tal que fueran los jueces y tribunales ordinarios los que planteasen, en caso de duda, la correspondiente cuestión prejudicial ${ }^{34}$; quedando reservado para el TC

33 Dictamen 2/2013, de 18 de diciembre de 2014; EU:C:2014:2454. Sobre la no adhesión al CEDH puede verse MARTín y PÉREZ DE NANClARES, J.: «El TJUE pierde el rumbo en el Dictamen 2/2013: ¿Merece todavía la pena la adhesión de la UE al CEDH?», RDCE , n. ${ }^{\circ} 52,2015$, pp. 825-869 y AzPITARTE SÁNCHEZ, M.: «Los derechos fundamentales de la Unión en busca de un nuevo equilibrio (Acerca del Dictamen 2/13 del Tribunal de Justicia, sobre la compatibilidad con los Tratados constitutivos del Proyecto de acuerdo internacional de adhesión de la Unión Europea al Convenio Europeo para la Protección de los Derechos Humanos y de las Libertades Fundamentales», REDC, n. ${ }^{\circ} 104,2015$, pp. 243-268.

34 En el Auto de 4 de octubre de 2011 (BVerfG, 1 BvL 3/08 vom 4.10.2011), el Tribunal Constitucional Federal alemán, estableció: a) que una cuestión de inconstitucionalidad con arreglo al art. 100, párrafo 1 , frase $1^{a}$ de la Constitución alemana sobre una ley que transpone Derecho de la Unión Europea no es admisible si el órgano judicial proponente de la cuestión no aclara si la ley de transposición que considera inconstitucional excede el margen de apreciación que el Derecho de la Unión Europea reconoce al legislador nacional; b) En su caso el órgano judicial proponente tiene que plantear a estos efectos la cuestión prejudicial 
el control de la aplicación del derecho de la Unión a través del recurso de amparo ex art. $24 \mathrm{CE}^{35}$. En definitiva, el Tribunal se dedicaría a controlar la actuación de los jueces y tribunales en relación con la aplicación del Derecho de la Unión y el planteamiento de la cuestión prejudicial, y, a la vez, conocería de los asuntos que no se encuentran en el ámbito el Derecho de la Unión, o, al menos, no plenamente (éste sería el caso Åkerberg Fransson ${ }^{36}$ ).

Si se considerara, por el contrario, que el Tribunal Constitucional es «órgano jurisdiccional» en el sentido de lo dispuesto en el art. 267 TFUE, como así se entendió por el Alto Tribunal en el ATC 86/2011, de 9 de junio, FJ 4 e), sus funciones y cánones deberían ser los mismos que los del resto de los órganos jurisdiccionales de los Estados miembros. El Tribunal Constitucional, como órgano jurisdiccional de la Unión, no puede quedar exento del cumplimiento de la Carta ni de la interpretación que de la misma haya realizado el Tribunal de Justicia, desconociendo el principio de competencia. De tal forma que, planteada ante él una cuestión cuyo objeto de control pertenece al ámbito de la Unión, debería plantear, de no encontrarse resuelta, la cuestión prejudicial en los mismos términos que los jueces ordinarios ${ }^{37}$, ya que a ningún órgano judicial, en ausencia de las condiciones de la doctrina de la doctrina Cilfit ${ }^{38}$, le compete interpretar el derecho de la Unión Europea, salvo al Tribunal de Justicia, y ningún órgano

ante el Tribunal de Justicia de acuerdo con el art. 267.1 TFUE, con independencia de si es o no un órgano de última instancia. Vid sobre el modelo alemán Arzoz SANTisteban, X.: La tutela de los derechos fundamentales..., op. cit., pp. 41 a 50.

35 Sobre esta posible solución, que califica de «tutela indirecta de la Carta a través del art. 24 CE», se pronuncia Arzoz Santisteban, X.: La tutela de los derechos fundamentales..., op. cit., capítulo IV, pp. 111 y ss.

36 STJUE 26 de febrero de 2013, C-617/10, asunto Åkerberg Fransson. En dicha Sentencia el TJUE afirmó que «en una situación en la que la acción de los Estados miembros no esté totalmente determinada por el Derecho de la Unión, las autoridades y Tribunales nacionales siguen estando facultados para aplicar estándares nacionales de protección de los derechos fundamentales, siempre que esa aplicación no afecte al nivel de protección previsto por la Carta, según su interpretación por el Tribunal de Justicia, ni a la primacía, la unidad y la efectividad del Derecho de la Unión (véase, en este sentido, la sentencia de 26 de febrero de 2013 , Melloni, C-399/11, apartado 60)» (apartado 29). Vid. un comentario sobre la citada Sentencia en HuELIN Martínez de Velasco, J.: «Las sentencias del Tribunal de Justicia de la Unión Europea Melloni y Akerberg Fransson (unas notas de urgencia)», Revista de Jurisprudencia El Derecho, n. ${ }^{\circ}$ 1, 2013.

37 Ha sido el propio Tribunal Constitucional el que en sus Sentencias ha entendido que la falta de planteamiento de la cuestión prejudicial por los órganos judiciales puede conllevar la vulneración del art. 24 CE (SSTC 58/2004, 194/2006, 78/2010 y 27/2013). También que el Tribunal Europeo de Derechos Humanos ha considerado que el no planteamiento de la cuestión prejudicial puede vulnerar, según qué casos, el derecho a un proceso equitativo reconocido en el art. 6.1 CEDH (STEDH de 8 de julio de 2014, caso Dhabi c. Italia). Por su parte, el Tribunal de Justicia se ha pronunciado sobre la responsabilidad de los Estados miembros por los incumplimientos imputables a sus órganos jurisdiccionales en las SSTJUE de 19 de noviembre de 1991, asunto Francovich y Bonifaci, C-6/90 y C-9/90; de 30 de septiembre de 2003, asunto Köbler, C-224/01; de 12 de noviembre de 2009, asunto Comisión/España; de 9 de septiembre de 2015, asunto Ferreira da Silva, C-160/14, y de 15 de noviembre de 2016, asunto Fernand Ullens de Schooten, C-298/15; vid. al respecto Cobreros Mendazona, E.: «Un paso más en la consolidación de la responsabilidad patrimonial de los Estados por incumplimiento judicial del Derecho de la Unión Europea (y en el reforzamiento de la cuestión prejudicial): la Sentencia 'Ferreira da Silva'», REDE, n. ${ }^{\circ}$ 58, 2016, pp. 83-107.

38 STJUE de 6 de octubre de 1982, asunto Cilfit. 
judicial puede depurarlo tras controlar su validez ${ }^{39}$. En materias de la Unión, no se trata sólo de interpretar los derechos constitucionales de conformidad con «la Declaración Universal de Derechos Humanos y los tratados y acuerdos internacionales sobre las mismas materias ratificados por España» (art. 10.2 CE), sino de actuar como Juez europeo ${ }^{40}$. Admitida su condición de órgano judicial a los efectos del art. 267 TFUE, ¿podría el Tribunal Constitucional, como tal, contradecir la jurisprudencia del TJUE en competencias de la Unión? ¿Y bajo qué razón? ¿Competencial? ¿Sustantiva? ${ }^{41}$

Evidentemente, el TJUE permite que el TC conozca de las cuestiones de inconstitucionalidad con fundamento en la protección de la Constitución pero, como ya avanzábamos en páginas anteriores, su decisión sobre la posible vulneración de derechos fundamentales quedará de alguna manera «en suspenso» hasta que quede confirmada por el TJUE, normalmente por la vía de la cuestión prejudicial. Es decir, aunque formalmente pueden coexistir dos decisiones con efectos diferentes —inaplicación e inconstitucionalidad-, puede afirmarse que, en la práctica, los Tribunales Constitucionales quedarán sometidos a la jurisprudencia del TJUE al igual que el resto de los órganos jurisdiccionales.

Considerar al Tribunal Constitucional como órgano judicial de la Unión tiene otra consecuencia nada desdeñable: supone admitir la posibilidad de la

39 STJUE de 22 de octubre de 1987, asunto Foto Frost.

40 No lo entiende así Matía Portilla, J.: «Primacía del derecho de la Unión y derechos constitucionales...», op. cit., pp. 479-522. Según Arroyo Jiménez, L.: «Los derechos fundamentales en la Unión Europea y el Tribunal Constitucional», op. cit., p. 361, el TC debe mantenerse, «en el momento presente» o «al menos por el momento», en su criterio de incorporar el Derecho de la Unión a través del art. 10.2 CE (STC 26/2014). Considera que «el Derecho de la Unión no requiere que los Tribunales Constitucionales de los Estados miembros acepten explícitamente su función de aplicación directa de la Carta siempre que ello no conduzca a resultados incompatibles con su primacía y efectividad». Para el citado autor, «el Derecho de la Unión permite que los Tribunales Constitucionales mantengan su propia narración constitucional, siempre que se adecúen materialmente a sus exigencias sorteando el conflicto entre los dos sistemas». En el mismo sentido que el expuesto en el texto, se pronuncian Rodríguez-IzQuierdo SERrano, M.: «Pluralidad de jurisdicciones y tutela de Derechos...», REDC, n. ${ }^{\circ} 107,2016$, pp. 133 y ss., afirmando que coincide con las apreciaciones de los votos particulares formulados a la Sentencia del TC en el asunto Melloni, «al considerar que, si el derecho de la UE es aplicable, la Carta tiene naturaleza imperativa y no solo interpretativa; y la sentencia del TJUE, naturaleza ejecutiva» (p. 135) y Arzoz Santisteban, X.: La tutela de los derechos fundamentales de la Unión europea, op. cit., pp. 87 y ss., quien en la nota 238 advierte de las distintas posturas doctrinales a favor y en contra de la vía interpretativa del art. 10.2 o el art. 93, ambos, de la CE; a las que añadimos las expuestas en líneas anteriores.

41 AzPitarte SÁnChez, M.: «Integración europea y legitimidad de la jurisdicción constitucional», RDCE, n. ${ }^{\circ}$ 55, 2016, p. 975, se pregunta, en este sentido, si «hemos de subsumir la Carta y la interpretación del Tribunal de Justicia bajo la regla general relativa al derecho internacional o gozan de un régimen específico de plena vinculación», para, a continuación, plantearse «qué debe hacer un Tribunal Constitucional con la Sentencia que resuelve su cuestión prejudicial». En su opinión, «la habilitación constitucional de atribución de competencias a la Unión opera aquí como un mandato de cumplimiento de sentencias del Tribunal de Justicia» y es el TC «el guardián de la Constitución, pero también de la apertura de la norma suprema, que exige un último acto de autoridad, la del Tribunal Constitucional, que pacifique definitivamente la controversia». Preocupado de la nueva situación del Alto Tribunal en el ámbito multinivel de los derechos fundamentales, considera que este «ha de desempeñar una labor de mediación entre los discursos constitucionales concurrentes», a través de lo que denomina «exportación/importación formal e informal» (pp. 972 y ss.). 
existencia de un doble estándar a aplicar. Es decir, el fijado por el TJUE en el ámbito de las competencias de la Unión y el establecido por el TC para las situaciones no cubiertas por el Derecho europeo. Es cierto que lo más probable es que ambos coincidan por su común vinculación a la jurisprudencia del TEDH, pero no siempre tiene que ocurrir así. En el caso Melloni, por ejemplo, el Tribunal Constitucional podría haber rebajado el canon de constitucionalidad, mantenido hasta ese momento en su jurisprudencia, únicamente respecto de los ciudadanos de la Unión y haberlo preservado íntegramente, en cambio, para el resto de los ciudadanos de terceros países ${ }^{42}$; y ello, además de por motivos competenciales, porque, a diferencia de la Unión, la relación con terceros Estados no está basada en elementos básicos como la confianza recíproca y el reconocimiento mutuo de las decisiones judiciales. En definitiva, el Tribunal podría, según la naturaleza de los casos, aplicar dos cánones o estándares diferentes dependiendo de la titularidad de las competencias - por ejemplo, distinguiendo, también, entre consumidores y no consumidores-, pues la declaración de lesión o de conformidad con la Carta, no tiene por qué conducir necesariamente a la misma conclusión en competencias del Estado y respecto de la Constitución.

Tras lo expuesto hay que decir que el TC no se ha pronunciado abiertamente sobre cuál es su modelo de resolución de este tipo de situaciones. Así, en los supuestos en los que se encontraba planteada una cuestión prejudicial, sus decisiones fueron adoptadas con posterioridad a los pronunciamientos del TJUE y siempre coincidiendo con su criterio; si bien ex art. 10.2 CE, al equiparar su vinculación a la de cualquier tratado internacional, y no por entender que sus decisiones lo están en aplicación del art. $93 \mathrm{CE}^{43}$. Dicho lo anterior, surgen algunas

42 Roca Trías, E., en su Voto concurrente a la STC 26/2014, FJ 6 d), expone, en este sentido, que «[l]a euroorden sustituye a la extradición en el marco de los países europeos, pero no en relación con países terceros, por lo que al no compartir los mismos principios, no se mostraba necesario ni, incluso, conveniente establecer un único canon de protección del derecho a la defensa». Y añade: «Precisamente por ello, y porque este Tribunal no se encuentra sometido al cumplimiento del Derecho de la Unión en materia de extradición con terceros países no integrados en la Unión Europea, no tiene por qué verse limitado a los estándares europeos. El canon, parámetro o estándar constitucional pudiera ser otro diferente; incluso haber permanecido el mismo, pero como consecuencia, y en este caso sí, de la aplicación del art. 10.2 CE». En la misma línea, Ollero Tassara, A., en su Voto concurrente a la STC 26/2014, FJ 2; y Carmona Contreras, A.: «El espacio europeo de los derechos fundamentales...», op. cit., p. 38. Al respecto, puede verse la STJUE de 6 de septiembre de 2016, asunto Aleksei Petrubhin, C-182/2015, en el que el Tribunal de Justicia ha declarado que «[e]n el supuesto de que un Estado miembro reciba una solicitud de un Estado tercero relativa a la extradición de un nacional de otro Estado miembro, este primer Estado miembro deberá comprobar que la extradición no vulnerará los derechos fundamentales a que se refiere el artículo 19 de la Carta de los Derechos Fundamentales de la Unión Europea».

43 Vid. por ejemplo la STC 35/2016, de 3 de marzo, asunto en el que se produjo un planteamiento simultáneo de la cuestión prejudicial y la cuestión de inconstitucionalidad por el TS, respecto del art. 5.1, párrafo segundo, de la Ley 25/1994, de 12 de julio, siendo previamente desestimada la primera por STJUE de 5 de marzo de 2009, asunto UTECA, C-222/07. En dicha Sentencia el TC declara que «la desestimación de una cuestión prejudicial planteada ante el Tribunal de Justicia de la Unión Europea no impide el planteamiento de una cuestión de inconstitucionalidad ante este Tribunal Constitucional en relación con el mismo precepto legal, pues una y otra jurisdicción tienen ámbitos diferentes (por todas, STC 28/1991, de 14 de 
preguntas que por ahora no tienen fácil respuesta: si el TC optara por considerarse juez europeo ¿implicaría ello una toma de posición difícil de revertir? ¿Podría el TC combinar ambas posturas según el criterio y las circunstancias de cada caso?

\section{CONCLUSIÓN}

Hay que ser conscientes del nuevo papel que les corresponde asumir a los Tribunales Constitucionales en las materias sujetas al Derecho de la Unión. La situación actual es radicalmente distinta de aquella en la que se establecieron los Tribunales Constitucionales con el poder que les otorgaban las respectivas Constituciones. Sin embargo, las posibles respuestas a este nuevo escenario se han planteado, en la mayoría de los casos, sobre una base precaria. La realidad es que, en cada país miembro de la UE, están en vigor dos sistemas jurídicos; cada uno con sus normas, sus fuentes del Derecho y sus reglas de aplicación. Los Tribunales Constitucionales europeos, entre ellos, obviamente, el español, deben ser capaces de distinguir ambas situaciones - interna y europea- para resolver de manera adecuada los distintos problemas que se vayan planteando. Es indudable que en virtud de la relación de primacía, la decisión vinculante, cuando lo que se discuta sea la aplicación de un derecho de la Carta en materias competencia de la UE, corresponderá al TJUE ${ }^{44}$. No pensamos, por ejemplo, que, dada la evolución de la Unión, tenga mucho recorrido seguir manteniendo, en nuestro caso, la equiparación del Derecho de la Unión (art. 93 CE) al Convenio Europeo de Dere-

febrero, FFJJ 4 a 6), ni condiciona el pronunciamiento de este Tribunal en esa cuestión de inconstitucionalidad», si bien, a reglón seguido, admite que la jurisdicción constitucional debe tener muy presentes las conclusiones alcanzadas por este último en ese proceso anterior sobre la misma medida ahora sometida a su control, y desestima la cuestión de inconstitucionalidad; vid. también sobre el planteamiento simultáneo por el mismo órgano judicial respecto de los arts. 17 y 540 LEC en relación al art. 1.535 CC, el ya citado ATC 168/2016, de 4 de octubre. De forma más reciente la STC 213/2016, de 15 de diciembre, resuelve un asunto en el que se planteó una cuestión prejudicial y un recurso de inconstitucionalidad, ambos, respecto de la Ley 1/2013, de 14 de mayo, de medidas para reforzar la protección a los deudores hipotecarios, reestructuración de deuda y alquiler social, y en el que el TC resolvió la pérdida de objeto parcial por cuanto la citada norma fue modificada a consecuencia de lo declarado por el Tribunal de Justicia en la Sentencia de 14 de marzo de 2013. Puede verse, también, aunque previa a las ya citadas, la STC 61/2013, de 14 de marzo que resolvía una cuestión de inconstitucionalidad planteada en relación con el inciso inicial de la letra a) de la regla segunda del apartado 1 de la disposición adicional séptima de la Ley general de la Seguridad Social, texto refundido aprobado por Real Decreto Legislativo 1/1994, de 20 de junio, en la redacción dada por el Real Decreto-ley 15/1998, de 27 de noviembre, por vulneración del art. 14 de la Constitución, tras el dictado de la STJUE de 22 de noviembre de 2012, asunto Elbal Moreno, que tenía por objeto la misma previsión normativa que estaba conociendo el Tribunal Constitucional.

44 Incluso la línea de actuación seguida por el Tribunal Constitucional Alemán — Sentencias Solange I y II, Maastricht, Lisboa o en la más reciente Sentencia de 15 diciembre de 2015-, ha finalizado, en mayor o menor medida, con la matización de su postura respecto de la aplicación del Derecho de la Unión. Vid. un comentario sobre dicha Sentencia ARzoz Santisteban, X.: «Karlsruhe rechaza la doctrina Melloni...», op. cit., pp. 109-141. 
chos Humanos o, es más, a un simple tratado internacional (art. 10.2 CE). Asumir que las relaciones entre el ordenamiento de la Unión y el ordenamiento estatal se rigen, también en el ámbito de los derechos y libertades fundamentales, por los principios de primacía y competencia, haría más fácil la relación entre Tribunales.

La realidad es tozuda y cuando esta, además, se constata, resistirse a ella «resulta un esfuerzo baldío» ${ }^{45}$. De no adaptarse, los Tribunales Constitucionales corren el riesgo de quedar desplazados de lo que es una tarea crucial: la configuración europea de los derechos fundamentales ${ }^{46}$. Por ello, entendemos que se ha de escoger un modelo de resolución que, respetando el principio de primacía, permita, a su vez, su participación en la misma. No caben posturas intermedias o equívocas que lo único a lo que pueden conducir es a incurrir en posibles vulneraciones de la Carta. Es en este momento en el que la jurisdicción constitucional «se encuentra, en la «encrucijada»» ${ }^{47}$, y debe decidir cuál quiere sea su posición en el entramado jurisdiccional de la Unión.

A nuestro juicio, su intervención, como órgano judicial a los efectos del art. 267 TFUE, es imprescindible, pues, en relación con el control de normas con rango de ley por vulneración de derechos fundamentales, la cuestión prejudicial se muestra como la fórmula más eficaz y respetuosa con los principios antes enunciados. Sólo asumiendo tal posición, podrá la jurisdicción constitucional, a través de su planteamiento, poner de manifiesto ante el Tribunal de Justicia todo aquello que estime pertinente en el ámbito de los derechos y libertades fundamentales, pudiendo modular, ex ante, una decisión que por ser competencia de la Unión, quedará finalmente tomada por el TJUE. De no ser así, serán los jueces y tribunales ordinarios los que participarán en dicha labor; máxime cuando el TC ha declarado, como ya ha quedado expuesto, que en caso de «doble vicio» se debe plantear la cuestión prejudicial con carácter previo a la cuestión de inconstitucionalidad. Una decisión que mengua, sin duda alguna, las posibilidades, no sólo de pronunciamiento por la jurisdicción constitucional sobre la posible vulneración de derechos fundamentales, sino, también, de participación directa en un proceso cada vez más intenso y en constante evolución.

$$
* * *
$$

45 García Couso, S.: «La participación del Tribunal Constitucional...», op. cit, p. 121.

46 Ibidem, p. 142. La citada autora no tiene duda de que el Tribunal Constitucional «debe de tener un papel destacado y no sólo residual en la construcción europea de los derechos y libertades fundamentales (...) en favor de lo que, en definitiva, es su función: la interpretación y, por ende, la protección y defensa de la Constitución como norma suprema del ordenamiento». Propone, por ello, en relación con el recurso de amparo, que «la participación en la configuración de la Europa de los derechos fundamentales», sea considerado un supuesto «autónomo» de especial trascendencia constitucional — no excluyente de los supuestos 'genéricos' previstos en la STC 155/2009-, que permita el dictado de sentencias tanto de creación de doctrina como de aplicación de la misma por el TC.

47 Ibidem. 
TITLE: Is dialogue between courts real? Preliminary references to the European Court of Justice and constitutional review on fundamental rights grounds

ABSTRACT: This paper purports to reflect on the complex issues that arise from the fact that both the European Court of Justice and the national constitutional court have the power to adjudicate on fundamental rights and that, therefore, on the basis of the application of different rules - the Charter of Fundamental Rights of the European Union and the national Constitution - they can occasionally arrive at different decisions. National courts are more and more aware of this dual avenue to challenge national regulations, through the preliminary reference to the ECJ and through the reference to the Constitutional Court of constitutional doubts with regard to national legislation. In consequence, national Constitutional Courts must accommodate into this new scenario.

RESUMEN: Es de sobra conocida la tensión existente entre los Tribunales Constitucionales de los Estados miembros y el Tribunal de Justicia de la Unión Europea a raíz del planteamiento de cuestiones prejudiciales ante el TJUE en supuestos en los que, aunque el asunto se plantee como una cuestión interpretativa del derecho de la Unión, comprende, además, un problema de derechos fundamentales susceptibles de ser controlados, también, constitucionalmente. Ambos procedimientos terminan con una decisión de compatibilidad con los derechos fundamentales. Este articulo pretende hacer una reflexión acerca de los problemas que suscita el hecho de que dos Tribunales - TJUE y TC - competentes en materia de protección de derechos fundamentales, y, al mismo tiempo, interpretadores de un mismo ordenamiento jurídico, puedan emitir juicios paralelos sobre una misma norma que ha sido sometida a su control y con parámetros diferentes de control: la Carta de Derechos Fundamentales de la Unión Europea y la Constitución.

KEY wORDS: Judicial Dialogue, reference for a preliminary ruling, constitutional review, Court of Justice of the European Union, Spanish Constitutional Court.

PALABRAS CLAVES: Diálogo entre Tribunales, cuestión prejudicial, control de constitucionalidad, Tribunal de Justicia de la Unión Europea, Tribunal Constitucional español.

FECHA DE RECEPCIÓN: 10.01.2017 FECHA DE ACEPTACIÓN: 01.02.2017 